\title{
Numerical and Experimental Studies on Heat Transfer Enhancement in a Circular Tube Inserted with Twisted Tape Inserts
}

\author{
Haoxu Liu, Guowei Zheng, Changzhong Man*, Ke Jiang, Xiaogang Lv \\ Internal Combustion Engine Research Institute, Dalian University of Technology, Dalian, China
}

Email address:

mcz640927@dlut.edu.cn (Changzhong Man)

${ }^{*}$ Corresponding author

\section{To cite this article:}

Haoxu Liu, Guowei Zheng, Changzhong Man, Ke Jiang, Xiaogang Lv. Numerical and Experimental Studies on Heat Transfer Enhancement in a Circular Tube Inserted with Twisted Tape Inserts. American Journal of Energy Engineering. Vol. 9, No. 2, 2021, pp. $30-40$.

doi: $10.11648 /$ j.ajee.20210902.12

Received: April 15, 2021; Accepted: May 19, 2021; Published: May 24, 2021

\begin{abstract}
Numerical simulations and experiments are carried out in this paper to research about characteristics of heat transfer, frictional resistance and comprehensive performance of turbulent water flow $(3000<\mathrm{Re}<10,000)$ in a circular tube with twisted tape inserts. A new type of twisted tape is proposed and it shows excellent performance on heat transfer enhancement. Effects of three parameters including twist ratio $(\mathrm{p} / \mathrm{w}=3,4,5)$, geometrical structure of alternation of clockwise and counterclockwise, existence of semicircular cuts are researched in simulations. The results show that lower twist ratio and the geometrical structure of alternation of clockwise and counterclockwise can enhance heat transfer while the existence of semicircular cuts can significantly reduce flow resistance. Experiments are conducted to validate the actual effect of the twisted tapes and the experimental results are basically consistent with the simulation results. Nusselt number and friction factor with the new type of twisted tape inserts are respectively 1.66-2.42 times and 4.36-4.97 times to that of plain tube while the maximum value of PEC (performance evaluation criteria) reaches 1.42 in experiments. The results of simulations and experiments indicate that the new type of twisted tape has a distinct advantage on heat transfer enhancement. Verification between simulations and experiments are carried out. The result shows that all deviations of corresponding values between simulations and experiments are within $15 \%$, which reflects that the numerical predications are basically in agreement with the experiment results. Finally, a comparative analysis was carried out with the new type of twisted tape in this paper and the different twisted tapes in the previous research. The new type of twisted tape proposed in this paper has higher Nusselt number and friction coefficient.
\end{abstract}

Keywords: Numerical Simulations, Heat Transfer Enhancement, Twisted Tape, Twist Ratio

\section{Introduction}

Since heat exchangers were applied in various industries such as oil industry, chemical industry, vehicle and aerospace, the efficiency of heat exchange has been an important factor affecting profits of enterprises. To improve the efficiency of heat exchange, a large number of researches about heat transfer enhancement were made [1-4]. The main methods of heat transfer enhancement could be divided into three aspects: active methods, passive methods and compound methods. Active methods require external power to be added into heat transfer system while passive methods don't have the requirement. Compound method is a hybrid technique which involves the use of both active and passive methods [5].

Twisted tape is one type of passive methods and has a distinct advantage on heat transfer enhancement than other methods. Inserting twisted tapes can enhance disturbance of fluid in the tube and produce swirl flow to increase heat transfer coefficient without big changes on structure of heat exchangers. There are many parameters affecting its effect on heat transfer enhancement such as pitch, twist ratio, width, thickness and other modifications on geometrical structure. So far, various experiments have been made to improve the efficiency of twisted tapes on heat transfer enhancement [6-8].

Sarada et al. made an experimental investigation on heat transfer enhancement in a circular tube with reduced width 
twisted tape inserts with air as working fluid [9]. The experimental results show that reduction in the width of tapes leads to reduction in Nusselt numbers as well as friction factors.

Hasanpour et al. did experimental research on heat transfer of double pipe heat exchanger. The experimental conditions were set as follows that the tube is inserted with typical, V-cut, $\mathrm{U}$-cut and pierced twisted tape inserts in turbulent water flow $(5000<\operatorname{Re}<15,000)$ for twist ratios $(\mathrm{p} / \mathrm{w}=3,5,7)$ [10]. All of the modified twisted tapes make $\mathrm{Nu}$ and $f$ higher, and different types of cuts have different effects on heat transfer enhancement.

Singh et al. carried out experimental investigations to study flow friction and heat transfer characteristics in a tubular heat exchanger inserted with different twisted tapes for the Re from about 6300-22,500) [11]. Pitch ratios $(1 / D=1,2)$ of the solid ring tubular and twist ratios $(\mathrm{p} / \mathrm{w}=2,3,4)$ of the twisted tapes are introduced into the core flow. The experimental results show that low twist ratio and pitch ratio can improve heat transfer characteristics and reduce friction factor.

Numerical simulation is also an effective means for scholars to research about heat transfer enhancement with twisted tape inserts in heat exchangers besides experiments and a great deal of researches about simulations of twisted tapes has been made [12-15].

Erika Y. Rios et al. did a numerical simulation of heat transfer of a non-Newtonian flow flowing through a circular tube inserted with twisted tapes at different twist ratios in stationary laminar regime [16]. The results indicated that lower twist ratio and higher Re performs better on the thermo-hydraulic performance.

Taiwo O. and Manosh C. carried out an investigation to analyze numerically flow and heat transfer characteristics in a circular tube inserted with different twisted tapes [17]. The different geometric model used are plain twisted tape (PTT), circular cut twisted tape (CCTT), elliptical cut twisted tape (ECTT), alternate-axis elliptical cut twisted tape (AECTT), triangular cut twisted tape (TCTT) et al. The results indicated that the type of cuts on the twisted tapes has effects on heat transfer characteristics. And the alternate-axis triangular cut twisted tape is the best on heat transfer enhancement.

Salman et al. did a numerical investigation on heat transfer and friction factor characteristics of $2 \%$ and $4 \%$ volume concentration of $\mathrm{Cu}$-water nanofluid flow in a tube with two types of vortex generator. Vortex generator are Parabolic-cut twisted tape and Classical twisted tape with different twist ratios and different cut depth [18]. The results indicated that the twist tape with $\mathrm{y}=2.93$ and $\omega=0.5 \mathrm{~cm}$ was more dominant for all Re.

In our present work, we are mainly engaged in heat transfer enhancement with twisted tape inserts in inner tube of heat exchangers. Based on a large number of references [19-21], we put forward a new type of twisted tape that has been little studied by experiments or numerical simulations, and it is twisted with alternation of clockwise and counterclockwise periodically and semicircular cuts uniformly distributed on both sides (ACCT tape with gap).

To improve the efficiency of heat transfer enhancement, simulations about twisted tapes of different parameters were carried out in this paper. Different twist ratios ( $\mathrm{p} / \mathrm{w}=3,4$ and 5) and different geometrical structure were applied in simulations and we made a comparison about their effects on improving heat transfer. Experiments were also made to validate actual effects of the twisted tapes. The results showed that the new type of twisted tape performed best both in simulations and experiments. The parameters involved in simulations and experiments are as follows:

$\begin{array}{ll}\text { Nomenclature } & \text { pitch of twisted tape, } \mathrm{mm} \\ p & \text { width of twisted tape, mm } \\ w & \text { twist ratio of twist tape } \\ p / w & \text { diameter of inner tube, mm } \\ D_{i} & \text { outlet temperature of hot water, } \mathrm{K} \\ T_{h}^{\text {out }} & \text { inlet temperature of hot water, } \mathrm{K} \\ T_{h}^{\text {in }} & \text { bulk temperature of hot water, } \mathrm{K} \\ T_{h} & \text { inlet temperature of cold water, } \mathrm{K} \\ T_{c}^{\text {in }} & \text { outlet temperature of cold water, } \mathrm{K} \\ T_{c}^{\text {out }} & \text { bulk temperature of cold water, } \mathrm{K} \\ T_{c} & \text { tube wall temperature of inner tube, } \mathrm{K} \\ T_{w} & \text { mean velocity of hot water, } \mathrm{m} / \mathrm{s} \\ U_{h} & \text { pressure drop, Pa } \\ \Delta P & \text { volume flow rate of hot water, } \mathrm{m}^{3} / \mathrm{s} \\ V_{h} & \text { volume flow rate of cold water, } \mathrm{m}^{3} / \mathrm{s} \\ V_{c} & \text { mass flow rate of hot water, } \mathrm{kg} / \mathrm{s} \\ W_{h} & \text { mass flow rate of cold water, } \mathrm{kg} / \mathrm{s} \\ W_{c} & \text { density of hot water at inlet temperature, } \mathrm{kg} / \mathrm{m}^{3} \\ \rho_{i n} & \text { density of hot water at bulk temperature, } \mathrm{kg} / \mathrm{m}^{3} \\ \rho_{h} & \text { specific heat capacity of hot water, } \mathrm{J} /(\mathrm{kg} \cdot \mathrm{K}) \\ C_{p h} & \text { specific heat capacity of cold water, } \mathrm{J} /(\mathrm{kg} \cdot \mathrm{K}) \\ C_{p c} & \end{array}$




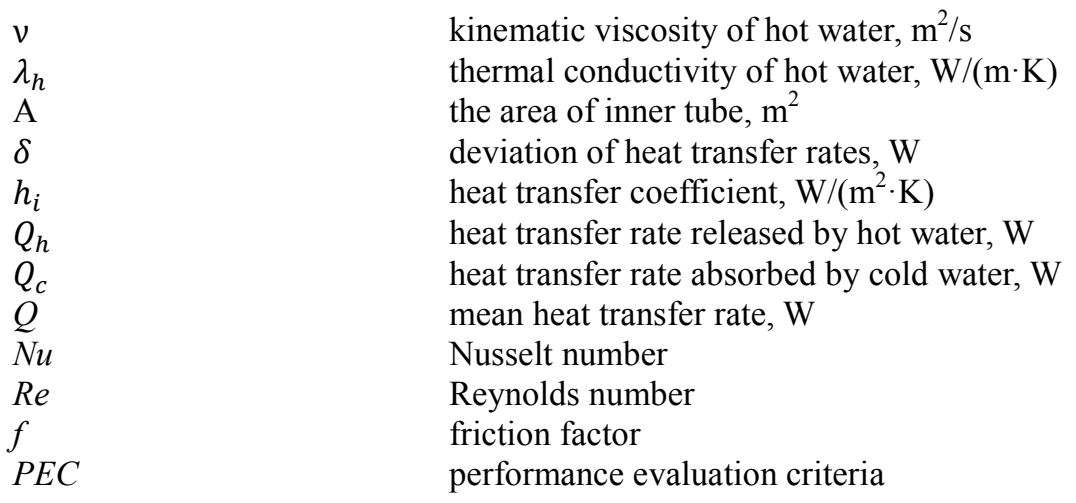

\section{CFD Modeling and Experimental Setup}

\subsection{Physical Models}

In our simulations, physical models are established with the software Pro/E and the pictures are shown in figure 1. Numerical calculation is conducted with ANSYS FLUENT. Physical models are respectively plain tube, typical twisted tapes (TT tape) of three twist ratio $(\mathrm{p} / \mathrm{w}=3,4,5)$, the twisted tape which is alternated with clockwise and counterclockwise periodically (ACCT tape) and the ACCT tape with semicircular cuts uniformly distributed on both sides (ACCT tape with gap). The length of the plain tube is $2400 \mathrm{~mm}$ and inner diameter is $16 \mathrm{~mm}$. The thickness of all the twisted tapes is $1 \mathrm{~mm}$ and the width is $14 \mathrm{~mm}$ with the pitch $42 \mathrm{~mm}$ for $\mathrm{p} / \mathrm{w}=3$. Gaps uniformly distributed on both sides of the ACCT tape are semicircular with the diameter $5 \mathrm{~mm}$.

Water was selected as working fluid in simulations and several assumptions were set up as follows [22]: (i) the flow in the tube is turbulent and incompressible; (ii) the flow is in steady state; (iii) natural convection and thermal radiation are neglected; (iv) thermal physical properties of the fluid are temperature independent. To simplify calculations, physical properties were set to be: $\rho=998.2 \mathrm{~kg} / \mathrm{m}^{3}, \mu=1.003 \times$ $10^{-3} \mathrm{~kg} / \mathrm{m} \cdot \mathrm{s}, \quad c_{p}=4182 \mathrm{~J} / \mathrm{kg} \cdot \mathrm{K}$ and $\lambda=0.6 \mathrm{~W} / \mathrm{m} \cdot \mathrm{K}$. Material of wall was elected as copper and material of twisted tapes was elected as aluminum while thickness of wall and heat conduction of twisted tapes are neglected.

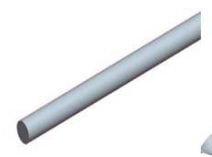

(a) plain tub

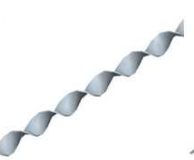

typical twisted tape

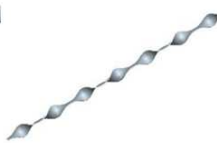

(c) ACCT tape

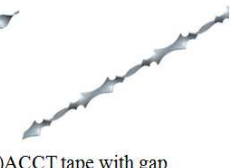

(d)ACCT tape with gap
Figure 1. Physical models of plain tube and twisted tapes in simulations.

\subsection{Governing Equations}

Numerical model in simulations is a two-equation turbulence model SST $k-\omega$ which consists of impact of low Reynolds number, impact of compressibility and shear flow diffusion. This SST $k-\omega$ model is based on transport equation of turbulence kinetic energy and specific dissipation rate and the transport equations are as follows:

$$
\begin{array}{r}
\frac{\partial}{\partial t}(\rho k)+\frac{\partial}{\partial x_{i}}\left(\rho k u_{i}\right)=\frac{\partial}{\partial x_{j}}\left(\Gamma_{k} \frac{\partial k}{\partial x_{j}}\right)+G_{k}-Y_{K} \\
\frac{\partial}{\partial t}(\rho \omega)+\frac{\partial}{\partial x_{i}}\left(\rho \omega u_{i}\right)=\frac{\partial}{\partial x_{j}}\left(\Gamma_{\omega} \frac{\partial \omega}{\partial x_{j}}\right)+G_{\omega}-Y_{\omega}+D_{\omega}
\end{array}
$$

The numerical model involves numerical solutions of the conservation equations for mass, momentum, and energy. These governing equations as follows:

Continuity Equation

$$
\frac{\partial \rho}{\partial t}+\frac{\partial\left(\rho u_{i}\right)}{\partial x_{j}}=S_{m}
$$

Momentum equation

$$
\begin{gathered}
\frac{\partial}{\partial t}\left(\rho u_{i}\right)+\frac{\partial\left(\rho \mathrm{u}_{\mathrm{i}} \mathrm{u}_{\mathrm{j}}\right)}{\partial x_{j}}=\frac{\partial \tau_{i j}}{\partial x_{j}}-\frac{\partial p}{\partial x_{i}}+\rho g_{i}+F_{i} \\
\tau_{i j}=\left[\mu\left(\frac{\partial u_{i}}{\partial x_{j}}+\frac{\partial u_{j}}{\partial x_{i}}\right)\right]-\frac{2}{3} \mu \frac{\partial u_{l}}{\partial x_{l}} \delta_{i j}
\end{gathered}
$$

Energy equation

$$
\frac{\partial(\rho T)}{\partial t}+\operatorname{div}(\rho u T)=\operatorname{div}\left(\frac{k}{C_{P}} \operatorname{grad} T\right)+S_{T}
$$

\subsection{Boundary Conditions}

Faces of the model were respectively defined as inlet, outlet, wall and inner-wall after meshing. The type of inlet was chosen to be velocity-inlet and temperature of fluid at the inlet was set to be a constant value $323 \mathrm{~K}$. The type of outlet was pressure-outlet and pressure of outlet was set to be 1 bar. Wall motion was set as

\begin{tabular}{|c|c|c|c|c|c|c|c|c|}
\hline flow rates/(L/h) & 100 & 120 & 140 & 160 & 180 & 200 & 220 & 240 \\
\hline $\begin{array}{l}\text { Reynolds number } \\
\text { heat flux } /\left(\mathrm{W} / \mathrm{m}^{2}\right)\end{array}$ & $\begin{array}{l}3736.09 \\
-12331 \\
\end{array}$ & $\begin{array}{l}4402.86 \\
-13878 \\
\end{array}$ & $\begin{array}{l}5093.47 \\
-14208 \\
\end{array}$ & $\begin{array}{l}5978.26 \\
-15658 \\
\end{array}$ & $\begin{array}{l}6738.54 \\
-16350 \\
\end{array}$ & $\begin{array}{l}7450.77 \\
-16866 \\
\end{array}$ & $\begin{array}{l}8197.85 \\
-17647 \\
\end{array}$ & $\begin{array}{l}8899.35 \\
-18235 \\
\end{array}$ \\
\hline
\end{tabular}
stationary wall under no slip shear condition and heat flux was set as constant values corresponding to each flow rate. The values of heat flux and flow rates in simulations of plain tube are given in table 1. Inner wall was set with default settings.

Table 1. Numerical values of heat flux and flow rates in simulations of plain tube. 
In the present numerical solution, the time-independent incompressible Navier-Stokes equations and the turbulence model are discretized using the finite volume method [23]. The standard pressure and second order upwind discretization schemes for momentum and energy equations are applied in the numerical models. The pressure-velocity coupling is handled by the "SIMPLE" algorithm. The computation is performed with the convergence criteria of $10^{-3}$ for continuity and velocities along each axis, $10^{-6}$ for energy.

\section{Data Reduction}

In this paper, researches about effect of heat transfer enhancement for single-phase forced convective flow with twisted tape inserts in a counter-flow heat exchanger were made with simulations and experiments. Nusselt number is adopted as an evaluation criterion of heat transfer characteristics and friction factor is calculated to reflect friction characteristics. Values of PEC were set as a comprehensive evaluation of heat transfer characteristics and friction characteristics. The formulas used in this paper are shown as follows.

The bulk temperature of hot water and cold water take the average value of the inlet and outlet temperature as:

$$
\begin{aligned}
& T_{h}=\frac{T_{h}^{\text {in }}+T_{h}^{\text {out }}}{2} \\
& T_{c}=\frac{T_{c}^{\text {in }}+T_{c}^{\text {out }}}{2}
\end{aligned}
$$

The mean temperature of wall temperature can be obtained as:

$$
\mathrm{T}_{\mathrm{w}}=\frac{\sum \mathrm{T}_{\mathrm{i}}}{8}
$$

The mean velocity of hot water is defined as:

$$
\mathrm{U}_{\mathrm{h}}=\frac{\mathrm{V}_{\mathrm{h}} \cdot \rho_{\mathrm{in}}}{\pi \cdot \mathrm{D}_{\mathrm{i}}^{2} \cdot \rho_{\mathrm{h}} / 4}
$$

The Reynolds number is defined as:

$$
\mathrm{R}_{\mathrm{e}}=\frac{\mathrm{U}_{\mathrm{h}} \cdot \mathrm{D}_{\mathrm{i}}}{\mathrm{v}}
$$

The heat transfer rates of two fluid streams could be obtained as:

$$
\begin{array}{r}
Q_{h}=\rho_{h} \cdot V_{h} \cdot C_{p h}\left(T_{h}^{\text {in }}-T_{h}^{\text {out }}\right) \\
Q_{c}=\rho_{c} \cdot V_{c} \cdot C_{p c}\left(T_{c}^{\text {in }}-T_{c}^{\text {out }}\right)
\end{array}
$$

The heat transfer rate of the heat transfer system take the mean value as:

$$
\begin{gathered}
\delta=\frac{\mathrm{Q}_{\mathrm{h}}-\mathrm{Q}_{\mathrm{C}}}{\mathrm{Q}_{\mathrm{h}}} \times 100 \% \\
\mathrm{Q}=\frac{\mathrm{Q}_{\mathrm{h}}+\mathrm{Q}_{\mathrm{C}}}{2}=\mathrm{h}_{\mathrm{i}} \mathrm{A}\left(\mathrm{T}_{\mathrm{h}}-\mathrm{T}_{\mathrm{w}}\right)
\end{gathered}
$$

The average heat transfer coefficient and Nusselt number could be obtained as follows formula:

$$
\begin{array}{r}
h_{i}=\frac{Q_{h}+Q_{c}}{2 A\left(T_{h}-T_{w}\right)} \\
N_{u}=\frac{h_{i} \cdot D_{i}}{\lambda_{h}}
\end{array}
$$

The friction factor is defined as:

$$
\mathrm{f}=\frac{\Delta \mathrm{P}}{\left(\rho \mathrm{U}_{\mathrm{h}}{ }^{2} / 2\right) \cdot\left(1 / \mathrm{D}_{\mathrm{i}}\right)}
$$

Values of performance evaluation criteria (PEC) is defined as following formula:

$$
\operatorname{PEC}=\frac{\mathrm{N}_{\mathrm{u}} / \mathrm{N}_{\mathrm{u} 0}}{\left(\mathrm{f} / \mathrm{f}_{0}\right)^{1 / 3}}
$$

Values of $\mathrm{Nu}$ calculated by empirical formulas could be obtained with the Gnielinski equation:

$$
\mathrm{Nu}_{\mathrm{f}}=\frac{(\mathrm{f} / 8)\left(\mathrm{R}_{\mathrm{e}}-1000\right) \operatorname{Pr}_{\mathrm{f}}}{1+12.7 \sqrt{\mathrm{f} / 8}\left(\mathrm{Pr}_{\mathrm{f}}{ }^{2 / 3}-1\right)}\left[1+\left(\frac{\mathrm{d}}{\mathrm{l}}\right)^{2 / 3}\right] \mathrm{c}_{\mathrm{l}}
$$

Values of $f$ calculated by empirical formulas could be obtained with Filonenko equation [24]:

$$
f=\left(1.82 \log R_{e}-1.64\right)^{-2}
$$

\section{Results and Discussion}

\subsection{Grid Independence}

Finite element meshing was conducted with the software Hypermesh and grids of models are shown in figure 2. The model of fluid in the plain tube was meshed with hexahedral grids and other models of fluid in tubes inserted with twisted tapes were meshed with tetrahedral grids. Considering that the boundary layer at the wall has a greater influence on heat transfer and flow, thus encrypted mesh density at the wall boundary layer.

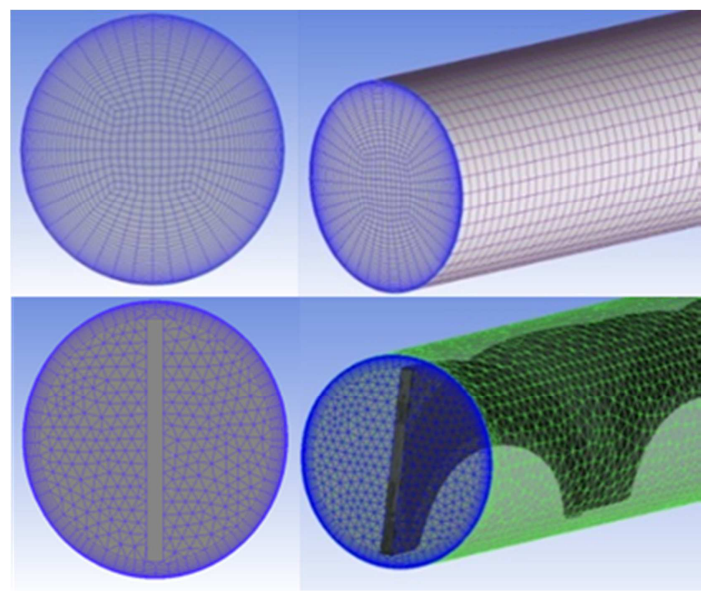

Figure 2. Grid model of plain and tube with twisted tape.

To testify accuracy of the numerical calculation, plain tube 
and typical twisted tape $(\mathrm{p} / \mathrm{w}=3)$ and ACCT tape were selected for grid independence test. Test results were shown in table 2 . The tests were conducted with the flow rate of $200 \mathrm{~L} / \mathrm{h}$ and different numbers of grids were obtained with different minimum element sizes. Evaluation criteria of the tests were based on Nusselt number and friction factor. All deviations of $\mathrm{Nu}$ and $f$ were within $4 \%$ when numbers of grids increase above values of the third level in table 2 for each model, which could verify the accuracy of the numerical calculation. Therefore, grid numbers of the third level in table 2 was adopted in simulations in consideration of simplifying calculation.

Table 2. Values of $\mathrm{Nu}$ and ffor the models with different grid numbers.

\begin{tabular}{llll}
\hline & Grid number & Nu & $\boldsymbol{f}$ \\
\hline & 716400 & 51.80 & 0.0358 \\
Plain tube & 798000 & 51.93 & 0.0359 \\
& 934175 & 52.18 & 0.0361 \\
& 1024800 & 52.31 & 0.0362 \\
Typical twisted & 1208372 & 67.80 & 0.1165 \\
tape_p/w=3 & 1486450 & 69.50 & 0.1176 \\
& 1830715 & 72.38 & 0.1258 \\
& 2480608 & 73.69 & 0.1272 \\
ACCT tape & 1193278 & 84.33 & 0.1757 \\
& 1428249 & 85.78 & 0.1783 \\
& 1890813 & 88.36 & 0.1783 \\
\hline
\end{tabular}

\subsection{Verification of Numerical Simulations}

Verification among simulation values and values calculated by empirical formulas in the plain tube were conducted for the accuracy of the. Values of Nusselt number and friction factor values in the numerical simulation of plain tube are respectively compared with values of $\mathrm{Nu}$ and $f$ calculated by Gnielinski equation and Filonenko equation. Values of Nusselt number and friction factor values are shown in figure 3 and figure 4. Deviations between simulation values and values calculated by empirical formulas are within $8 \%$. This can basically reflect the accuracy of the numerical simulations.

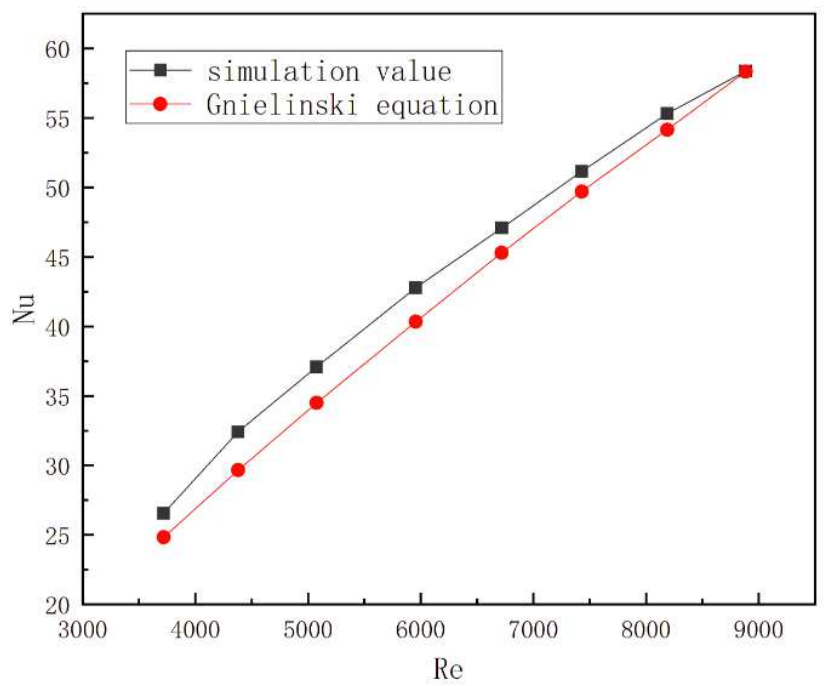

Figure 3. Values of $\mathrm{Nu}$ calculated by simulations and empirical formulas in the plain tube.

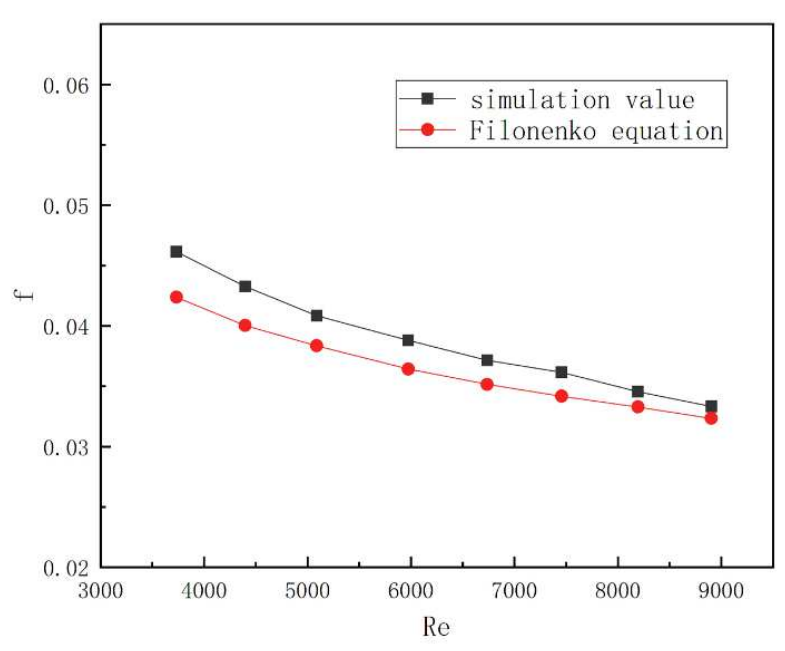

Figure 4. Values of $f$ calculated by simulations and empirical formulas in the plain tube.

\subsection{Simulations with Typical Twisted Tape Inserts of Three Different Twist Ratios}

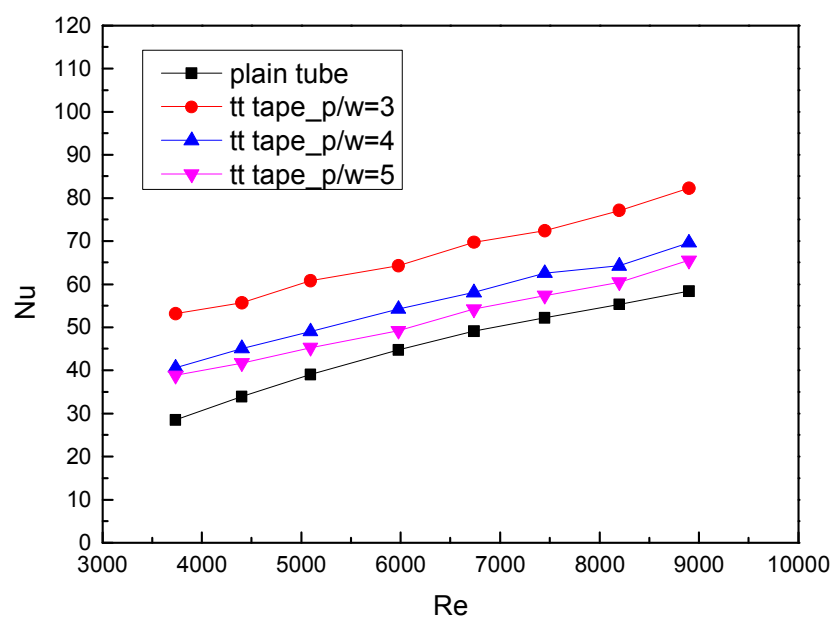

Figure 5. Nusselt number with twisted tapes of different twists ratios.

Typical twisted tapes of three twist ratios $(\mathrm{p} / \mathrm{w}=3,4,5)$ were adopted in our simulations to research about effects of twist ratio on the efficiency of heat transfer enhancement. Characteristics of heat transfer, frictional resistance and comprehensive performance in this research are respectively based on $\mathrm{Nu}, f$ and PEC. As shown in figure 5, all Nusselt number with twisted tape inserts are higher than that in the plain tube, which means heat transfer characteristics were enhanced with twisted tape inserts. Nusselt number increase with the increment of Reynolds number while the ratios of Nusselt number with twisted tape inserts to Nusselt number in the plain tube decrease correspondingly. That means effects of twisted tapes on heat transfer enhancement are more significant in low Reynolds number for turbulent flow. It can be seen that the twisted tape of twist ratio $\mathrm{p} / \mathrm{w}=3$ performs better on heat transfer enhancement among the three different twist ratios from the comparison. It can be explained by the reason that twisted tape of a lower twist ratio with a more intensive spiral structure produces more swirl flow and 
disturbance for fluid in the tube. The fluid in the central position of the tube is also fully mixed with fluid near the tube wall.

Besides, a more intensive spiral structure leads in more flow resistance and the values of $f$ with the twisted tape of twist ratio $\mathrm{p} / \mathrm{w}=3$ are larger than the other two twist ratios as shown in figure 6. Friction factor decrease with the increment of Reynolds number and the ratios of $f$ with the twisted tape inserts to $f$ in the plain tube decrease correspondingly. A lower twist ratio with a more intensive spiral structure has more influence on changes of the flow path and stability of flow in the tube resulting in the increase of flow resistance.

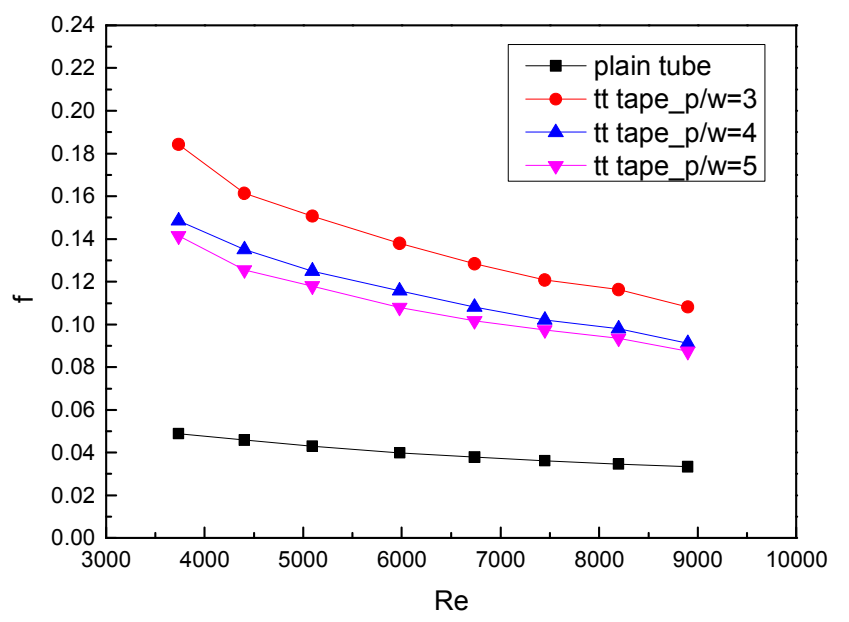

Figure 6. $f$ with twisted tapes of different twists ratios.

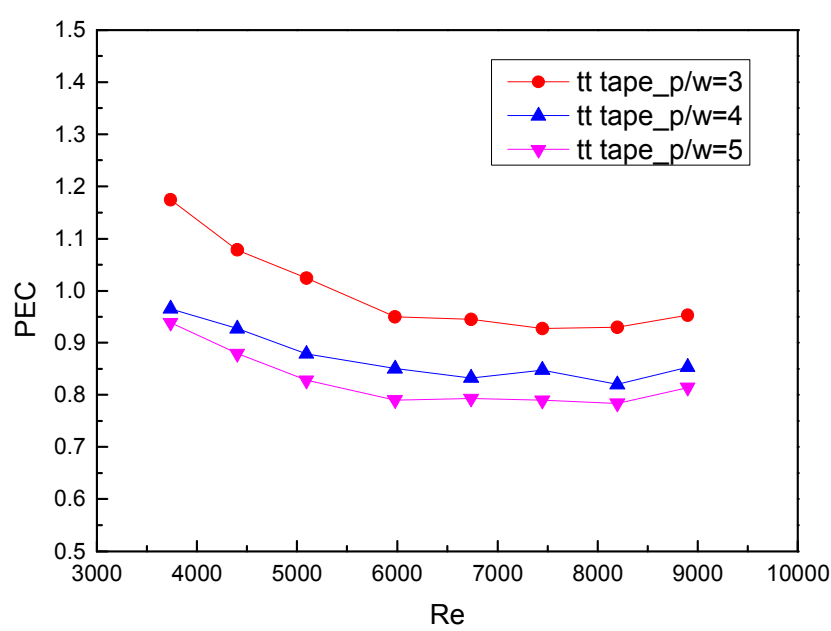

Figure 7. PEC with twisted tapes of different twists ratios.

PEC is adopted in this research as a comprehensive evaluation between heat transfer characteristics and friction characteristics. The values of PEC with twisted tapes of different twists ratios are shown in figure 7 . The twisted tape of twist ratio $\mathrm{p} / \mathrm{w}=3$ obtains the highest value of $\mathrm{PEC}$ ranging from 0.93 to 1.17 while values of the twisted tapes with twist ratio $\mathrm{p} / \mathrm{w}=4$ and $\mathrm{p} / \mathrm{w}=5$ are $0.82-0.96$ and $0.78-0.94$, respectively. That means the twisted tape of twist ratio $\mathrm{p} / \mathrm{w}=3$ has the best comprehensive performance on enhancing heat transfer.
As seen from figures 5-7, the twisted tape of twist ratio $\mathrm{p} / \mathrm{w}=3$ performs best on heat transfer enhancement among the three twist ratios in simulations. Figure 8 shows velocity contours and temperature contours of fluid at the outlet of the tube with twisted tape inserts of three twist ratios $(\mathrm{p} / \mathrm{w}=3,4,5)$ at flow rate of $200 \mathrm{~L} / \mathrm{h}$. As seen from the velocity contours, inserting twisted tapes in the tube generates two swirls on both sides of twisted tape and produces second flow in the tube. Velocities of fluid in the swirls are faster than other regions of the tube and velocities of fluid near the tube wall are enhanced with twisted tape inserts, which symbolizes destroying of the boundary layer and mixing of fluid in the tube. Temperature contours show that inserting twisted tapes makes temperature distribution of fluid more uniform in condition of being cooled with constant heat fluxes. This indicates fluid in the tube is fully mixed by inserting twisted tapes to achieve heat transfer enhancement. It is obvious that temperature of fluid in the tube inserted with the twisted tape of twist ratio $\mathrm{p} / \mathrm{w}=3$ is lower than that with twisted tapes of the other two twist ratios, which indicates the twisted tape of twist ratio $\mathrm{p} / \mathrm{w}=3$ has best performance on improving heat transfer among the three twisted tapes of different twist ratios.

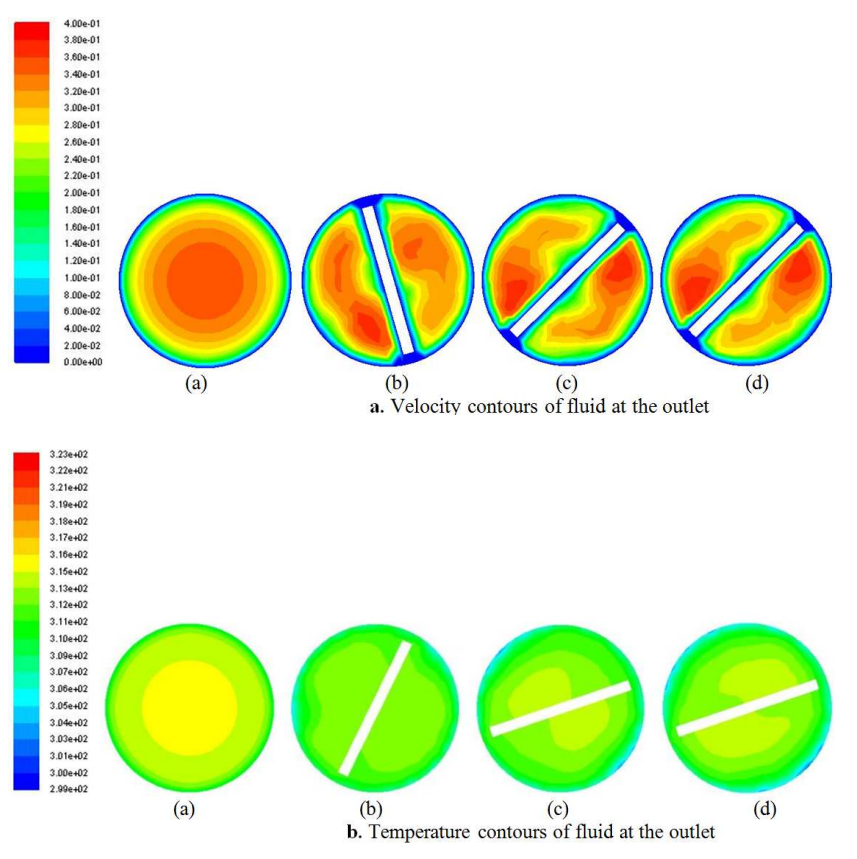

Figure 8. Velocity contours and temperature contours of fluid at the outlet: (a) Plain tube; (b) With twisted tape of $p / w=3$; (c) With twisted tape of $p / w=4$; (d) With twisted tape of $p / w=5$.

\subsection{Simulations with ACCT Tape and ACCT Tape with Gap}

To research the effects of modification for geometrical structure of the typical twisted tape on heat transfer enhancement, the twisted tape which is twisted with alternation of clockwise and counterclockwise periodically (ACCT tape) was adopted in simulations. Another ACCT tape with semicircular cuts uniformly distributed on both sides (ACCT tape with gap) was presented for further modification. Twist ratio of all twisted tapes in this simulation was adopted with $\mathrm{p} / \mathrm{w}=3$ for the typical twisted tape of this twist ratio 
performs best on heat transfer enhancement in above simulations. Comparisons about heat transfer characteristics and friction characteristics with different twisted tape inserts are shown in following figures. As seen from figure 9, the ACCT tape obtains the highest values of $\mathrm{Nu}$ and the two ACCT tapes both show better heat transfer characteristics than the typical twisted tape. This indicates the modifications for geometrical structure of the typical twisted tape achieve positive effects on heat transfer enhancement. It can be seen that the existence of gaps slightly reduces effects of the ACCT tape on heat transfer characteristics.

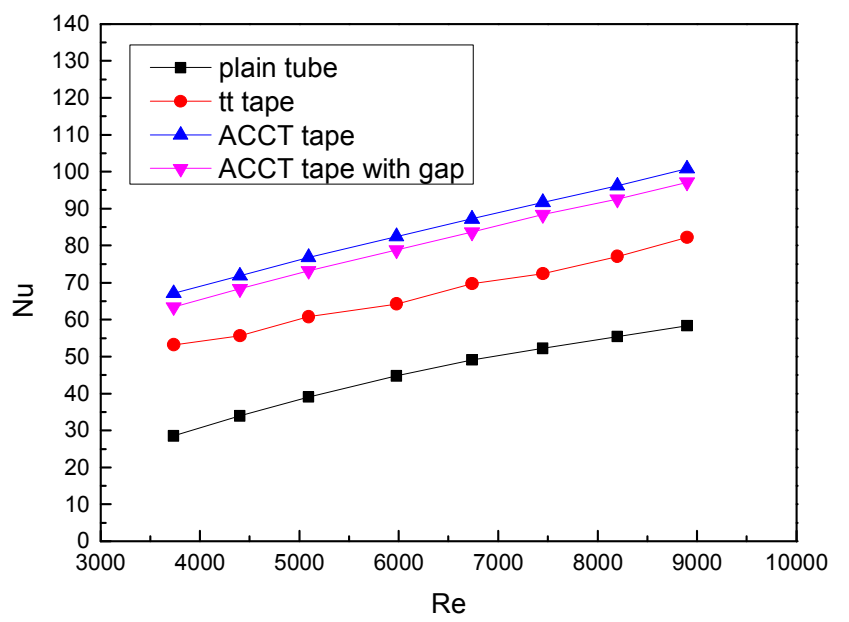

Figure 9. Nusselt number with different twisted tapes.

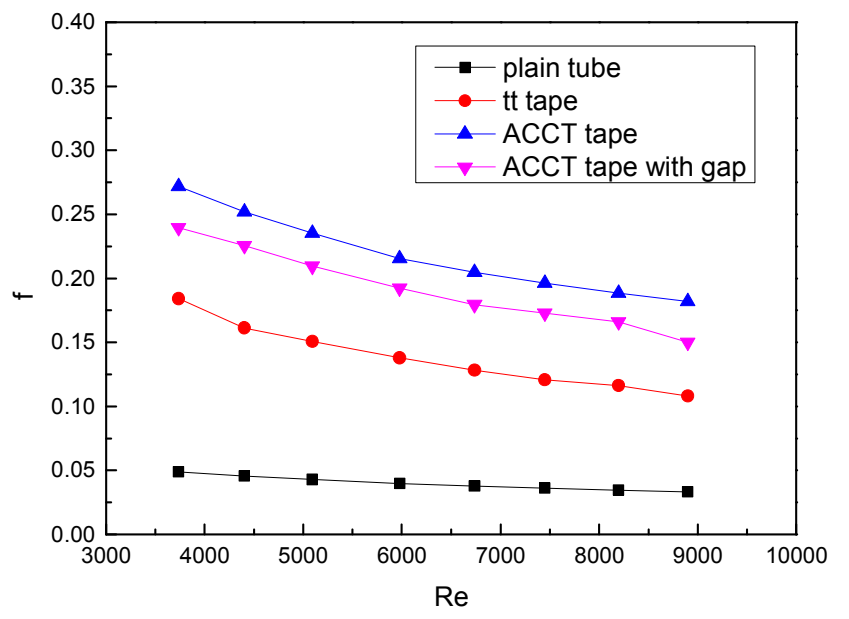

Figure 10. $f$ with twisted tapes of different twist tapes.

Figure 10 shows values of friction factor with different twisted tape. As seen from the figure, values of $f$ with the ACCT tape are higher than that with the ACCT tape with gap and that are much higher than values with the typical twisted tape. This means the modifications for geometrical structure of the typical twisted tape increase flow resistance of fluid in the tube. However, there is a significant reduction for values of $f$ with the ACCT tape with gap in comparison with that with the ACCT tape. The ratios of $f$ with ACCT tape to that in the plain tube are 5.44-5.69 while the values are 4.69-4.87 for the ACCT tape with gap and values of $f$ reduce by 11.0-16.7 percent inserting the ACCT tape with gap in the tube. It can be seen that the existence of gaps significantly reduces flow resistance in comparison with inserting the ACCT tape in the tube.

Figure 11 shows Values of PEC with different twisted tape. There is no big disparity between values of PEC with the ACCT tape and that with the ACCT with gap. In Reynolds number 6000-9000, the ACCT tape with gap obtains higher values of PEC than the ACCT tape. Both the two ACCT tapes obtain higher values of PEC compared with the typical twisted tape. As a conclusion, the ACCT tape has a greater advantage than the typical twisted tape on heat transfer enhancement and the existence of gaps on the ACCT tape can partly improve the efficiency of heat transfer enhancement with a distinct advantage of material saving.

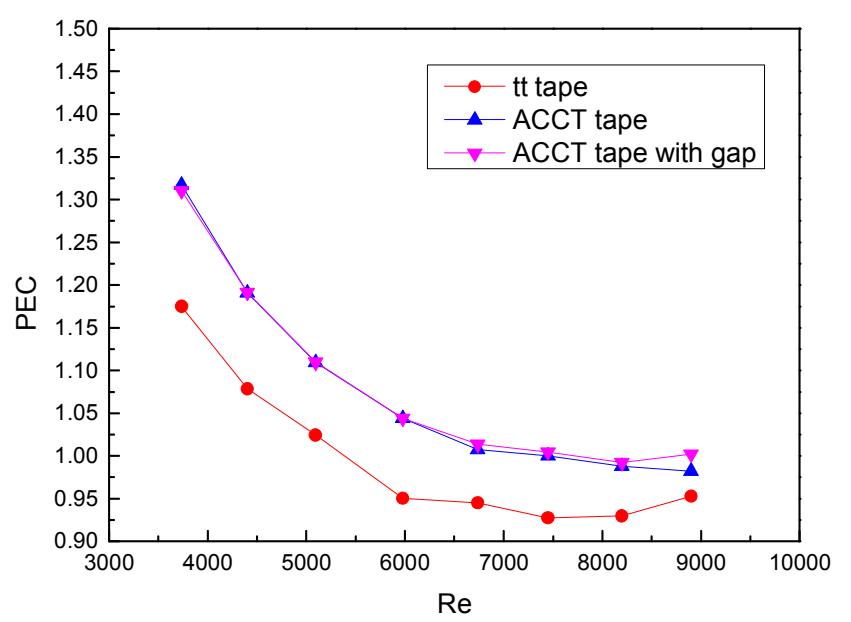

Figure 11. Values of PEC with different twisted tapes.

Figure 12 shows velocity contours and temperature contours at the outlet of the tube with different twisted tape inserts at the flow rate of $200 \mathrm{~L} / \mathrm{h}$. As seen from the velocity contours, swirls on both sides of twisted tapes are more obvious and velocities of fluid in the swirls are faster for inserting the ACCT tape in comparison with the typical twisted tape. That means flowing conditions with ACCT tape inserts are of more intensive disturbance than that with the typical twisted tape insert. The structure of the ACCT tape enhances disturbance of fluid and increases residence time of fluid in the tube resulting in fully mixing of fluid and generation of swirl flow, which is the reason that more flow resistance exists in the tube with inserting ACCT tapes than inserting typical twisted tapes. The temperature contours reflect temperature distribution of the fluid in the tube and it's obvious that temperature distribution with ACCT tape inserts is more uniform than that with the typical tape insert. This indicates that ACCT tapes perform better on heat transfer characteristics than the typical twisted tape. There is little difference on velocity contours and temperature contours between the tube with the ACCT tape and the tube with the ACCT tape with gap. 

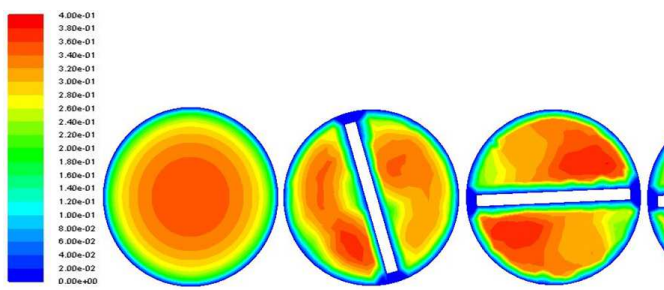

(c)

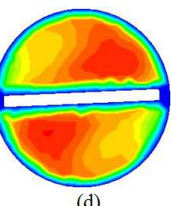

a. Velocity contours of fluid at the outlet

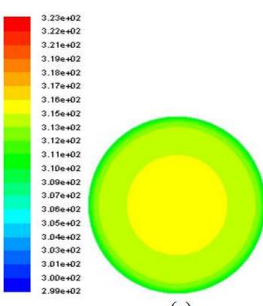

(a)

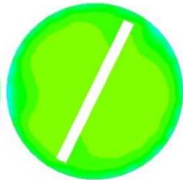

(b)

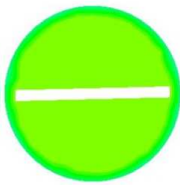

(c)

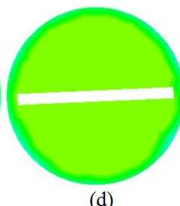

Figure 12. Velocity contours and temperature contours of fluid at the outlet: (a) Plain tube; (b) with typical twisted tape; (c) with ACCT tape; (d) with ACCT tape with gap.

\subsection{Experimental Setup}

To validate actual effect of the new type of twisted tapes, the experiments of plain tube and the tubes with twisted tape inserts were made. The experimental device consists of a double tube heat exchanger, a water flow system and its accessories. The hot water in the inner pipe is cooled, while the cold water acts as the cooling fluid between the inner and outer pipes of the double tube heat exchanger. It is the reason that heat fluxes were regarding as constant values in boundary condition of simulations due to little difference on heat capacities between hot water and cold water. Eight flow rates of hot water are applied in experiments ranging from $100 \mathrm{~L} / \mathrm{h}$ to $240 \mathrm{~L} / \mathrm{h}$ and flow rate of cold water is kept at $200 \mathrm{~L} / \mathrm{h}$. The experimental system diagram is shown in figure 13 and twisted tapes used in experiments are shown in figure 14.

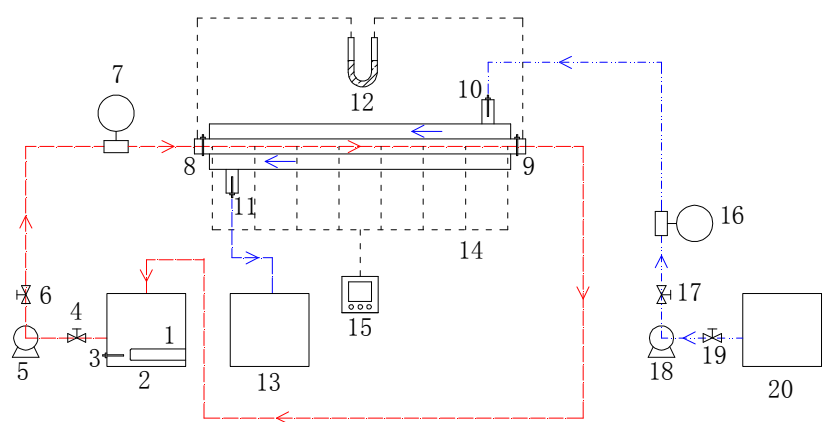

Figure 13. Layout of the experimental system.

1. Heater; 2. Hot water tank; 3. RTD-hot water in tank; 4. Ball valve; 5. Hot water pump; 6 . Hot water control valve; 7. Flowmeter; 8 . RTD-hot water inlet; 9. RTD-hot water outlet; 10. RTD-cold water inlet; 11. RTD-cold water outlet; 12. U-tube manometer; 13. Cold water recoverer; 14. Thermocouples; 15. Data logger; 16. Flowmeter; 17. Cold water control valve; 18. Cold water pump; 19. Ball valve; 20. Cold water tank

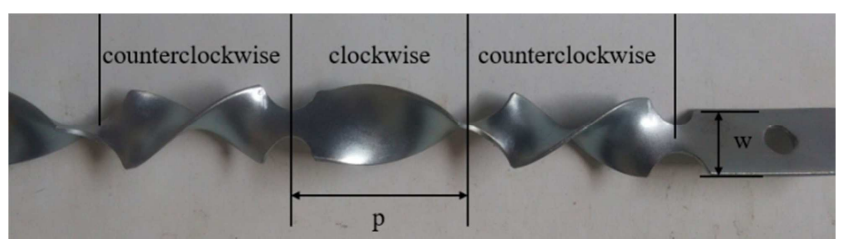

a. The ACCT tape

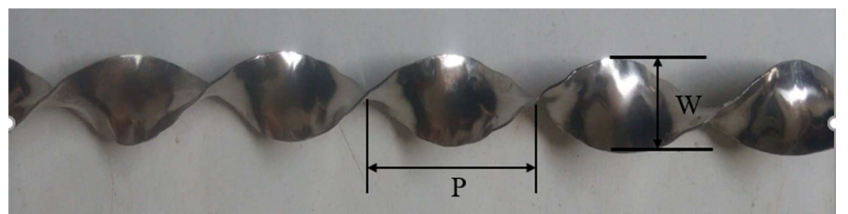

b. The typical twisted tape

Figure 14. Twisted tapes used in experiments.

\subsection{Verification of Experimental Facility}

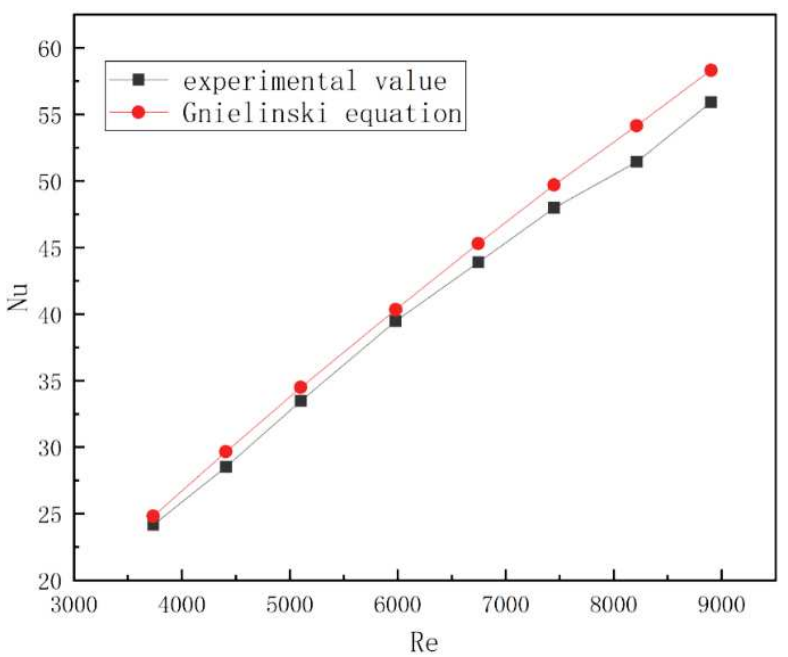

Figure 15. Values of $\mathrm{Nu}$ calculated by experiments and empirical formulas in the plain tube.

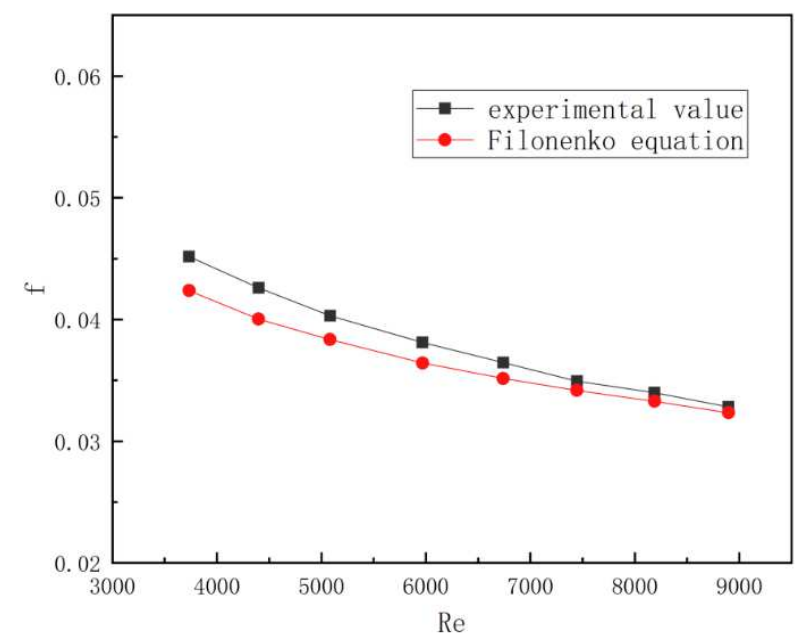

Figure 16. Values of $f$ calculated by experiments and empirical formulas in the plain tube.

Verification among experimental values and values calculated by empirical formulas in the plain tube were 
conducted for the accuracy of the experimental system. Values of Nusselt number and friction factor in the experiment of plain tube are respectively compared with values of Nusselt number and friction factor calculated by Gnielinski equation and Filonenko equation. Values of $\mathrm{Nu}$ and $f$ are shown in figure 15 and figure 16. Deviations between experimental values and values calculated by empirical formulas are within $6 \%$. This can basically reflect the accuracy of the experimental system.

\subsection{Verification Between Simulations and Experiments}

In above simulations, the ACCT tape with gap of twist ratio $\mathrm{p} / \mathrm{w}=3$ achieve the best effects on heat transfer enhancement. To validate actual effect of this new type of twisted tape, experiments were conducted and comparisons about values of $\mathrm{Nu}, \mathrm{f}, \mathrm{PEC}$ among plain tube, typical twisted tape and the ACCT tape with gap were made. The results are shown in following figures. Figure 17 shows values of Nu, $f$ and PEC in simulations and experiments. It can be seen that values of $\mathrm{Nu}$ and $f$ in simulations are a little higher than that in experiments and values of PEC in simulations are lower than that in experiments. All deviations of corresponding values between simulations and experiments are within $15 \%$, which reflects that the numerical predications are basically in agreement with the experiment results. Values of $\mathrm{Nu}$ with the ACCT tape are higher than that with the typical twisted tape whether in simulations or experiments and it shows the superiority of the ACCT tape on heat transfer characteristics. Values of $f$ with the ACCT tape are also higher than that with the typical twisted tape for the increase of flow resistance caused by modifications of the typical twisted tape. In the experiments, the highest value of PEC is obtained with the ACCT tape at Reynolds number 3700 and the values are 1.02-1.42 in experimental flowing conditions with the ACCT tape while values are 0.96-1.36 with the typical twisted tape. The experimental results have further confirmed that the ACCT tape with gap makes excellent effects on heat transfer enhancement and has an obvious advantage in comparison with the typical twisted tapes.

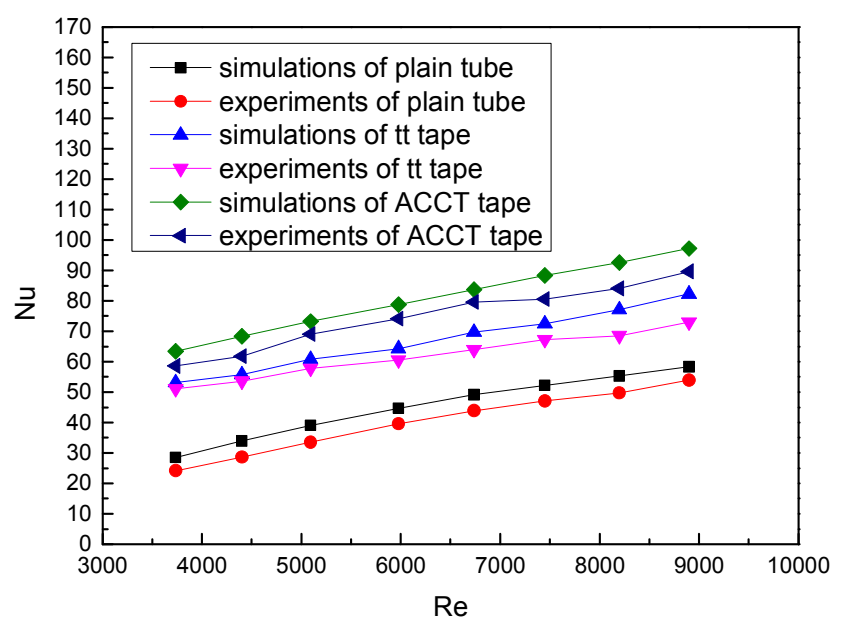

a. Values of Nusselt number in simulations and experiments with different twisted tape inserts

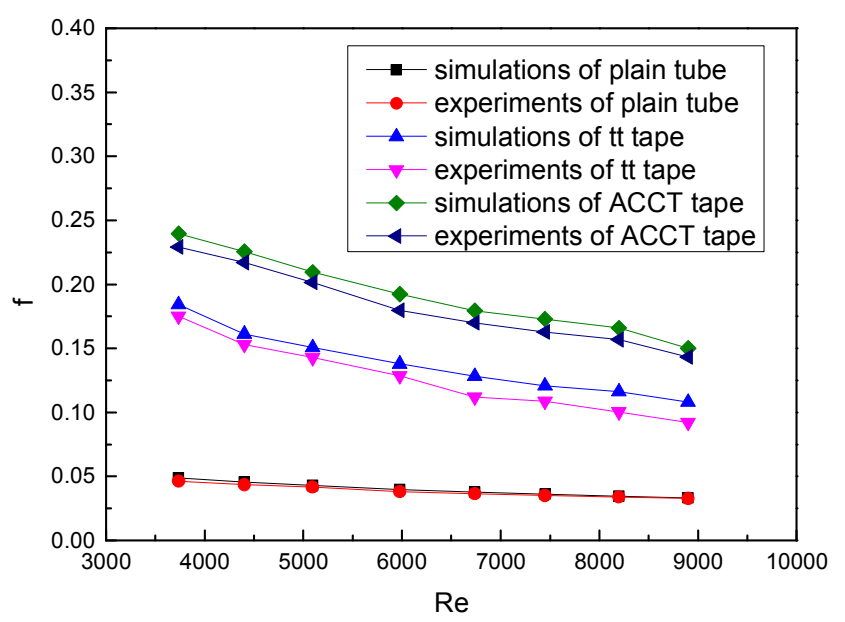

b. Values of $f$ in simulations and experiments with different twisted tape inserts

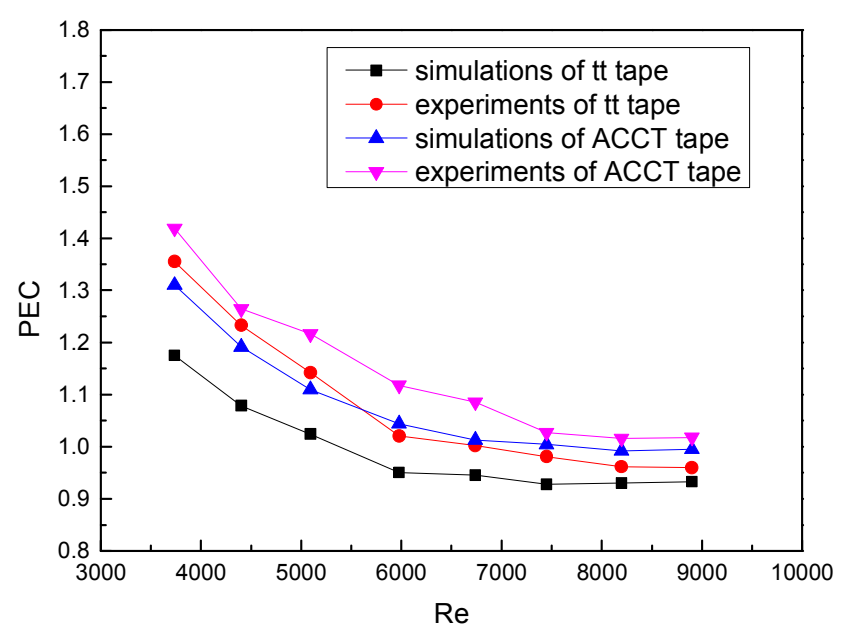

c. Values of PEC in simulations and experiments with different twisted tape inserts

Figure 17. Comparison of values of $N u$, $f$ and PEC between simulations and experiments.

\subsection{Comparison Between ACCT Tape with Gap and Other Twisted Tapes}

The Nusselt number $(\mathrm{Nu})$ and friction factor $(f)$ versus Reynolds number for tube fitted with the ACCT tape with gap and other twisted tapes reported in previous papers [25-27] are shown in Figures 18 and 19. Table 3 shows the geometries of different twisted tapes reported in previous paper. As shown in the figure, at the same Reynolds number the Nusselt number with ACCT tape with gap in this study is higher than the STT, VTT and TTT by P. Murugesan et al in the Reynolds number is smaller than 8000 . Only after the Reynolds number is greater than 8000 , the Nusselt number is slightly smaller than the STT. However, the values of $f$ with ACCT tape with gap in this study is slightly higher than the twisted tapes by $\mathrm{P}$. Murugesan et al. 
Table 3. Different twisted tapes reported in previous paper.

P. Murugesan et al [25] STT
P. Murugesan et al [26] VTT
P. Murugesan et al [27] TTT

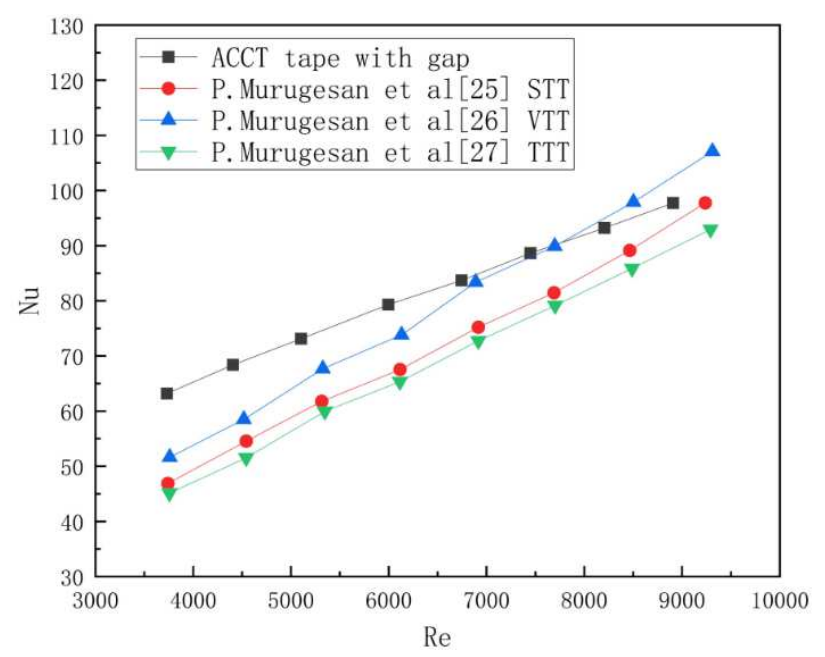

Figure 18. Values of Nusselt number with different twisted tapes in different literatures.

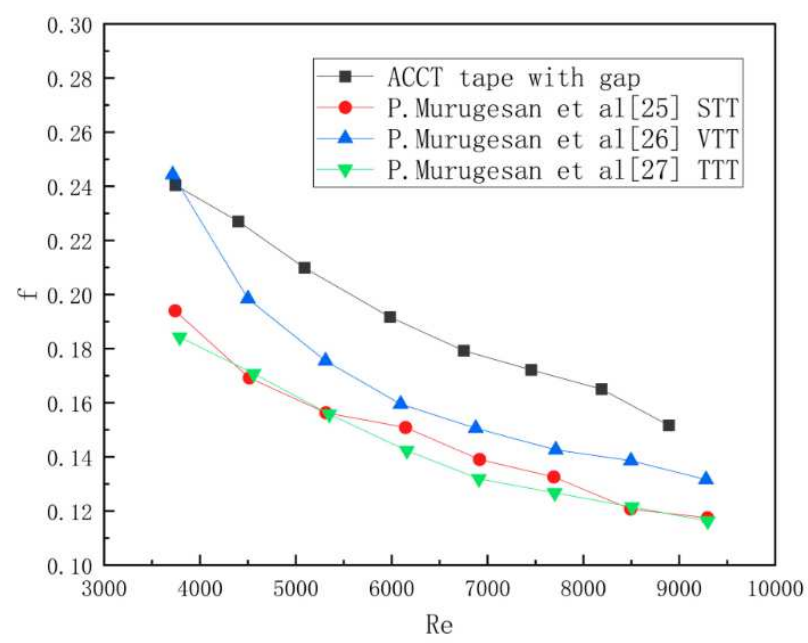

Figure 19. Values of $f$ with different twisted tapes in different literatures.

\section{Conclusions}

In the present paper, simulations and experiments among plain tube, tubes inserted with typical twisted tape and tubes inserted with the ACCT tapes are carried out to research the effects of different twisted tapes on heat transfer enhancement in turbulent flowing conditions $(3000<\operatorname{Re}<10,000)$. The parameters of twisted tapes in the research includes twist ratio $(\mathrm{p} / \mathrm{w}=3,4,5)$, geometrical structure of alternation of clockwise and counterclockwise, existence of semicircular cuts. Characteristics of heat transfer, frictional resistance and comprehensive performance in this research are respectively based on $\mathrm{Nu}, f$ and PEC. Following conclusions can be drawn:

The twisted tape with a lower twist ratio leads in more disturbance of fluid in the tube and has a better effect on heat transfer. The twisted tape with twist ratio $\mathrm{p} / \mathrm{w}=3$ obtain the highest values of $\mathrm{Nu}, f$ and $\mathrm{PEC}$ in the simulations among different twist ratios.

The ACCT tape has a significant advantage on heat transfer enhancement than typical twisted tapes. Values of $\mathrm{Nu}$ and PEC with the ACCT tape inserts are respectively 1.24-1.28, 1.05-1.13 times to that with the typical twisted tape.

The existence of gaps on the ACCT tapes can obviously reduce frictional resistance on the basis of little influence on heat transfer with a distinct advantage of material saving. Values of friction factor reduce by 11.0-16.7 percent inserting the ACCT tape with gap than inserting the ACCT tape in the tube.

The numerical predications are reasonably in agreement with the experiment results and the ACCT tape with gap performs best on heat transfer enhancement whether in simulations or experiments. Values of PEC are respectively $0.99-1.31,1.02-1.42$ in simulations and experiments, which are nearly 8 percent and 6 percent higher than that with the typical twisted tape of the same twist ratio on average.

\section{References}

[1] Gugulothu S K. Experimental investigation on heat transfer and pressure drop characteristics in a smooth tube with different twisted tape inserts [J]. Heat Transfer-Asian Research, 2019, 48 (1).

[2] Dalkl A S, Ulu B, Cellek M S, et al. Single phase flow heat transfer characteristics of quad-channel twisted tape inserts in tubes [J]. International Communications in Heat and Mass Transfer, 2020, 118: 104835.

[3] Li P, Peng L, Liu Z, et al. Experimental and numerical study on the heat transfer and flow performance for the circular tube fitted with drainage inserts [J]. International Journal of Heat and Mass Transfer, 2017, 107 (apr.): 686-696.

[4] Ruengpayungsak K, Kumar M, Chuwattanakul V, et al. Experimental Study of the Effects of Inclusion of RectangularCut Twisted Tapes on Heat Transfer and Pressure Drop in a Round Tube [J]. Arabian Journal for Science and Engineering, 2019, 44 (12): 10303-10312.

[5] Varun, M. O. Garg, Himanshu Nautiyal, Sourabh Khurana, M. K. Shukla, Heat transfer augmentation using twisted tape inserts: A review, Renewable \& Sustainable Energy Reviews 63 (2016) 193-225.

[6] Sivakumar K, Rajan K. Experimental Investigation of Heat Transfer Characteristics in a Circular Tube Fitted with Triangular-Cut Twisted Tape (TCTT) Inserts. 2018. 
[7] Sompol Skullong, Pongjet Promvonge, Chinaruk Thianpong, Monsak Pimsarn, Heat transfer and turbulent flow friction in a round tube with staggered-winglet perforated-tapes, International Journal of Heat \& Mass Transfer, 95 (2016) 230-242.

[8] Kosker M, Yilmaz F. The cross-sectional curvature effect of twisted tapes on heat transfer performance [J]. Chemical Engineering and Processing, 2020, 154: 108008.

[9] S. Naga Sarada, A. V. Sita Rama Raju, K. Kalyani Radha, L. Shyam Sunder, Enhancement of heat transfer using varying width twisted tape inserts, 2.6 (2010) 1-10.

[10] A. Hasanpour, M. Farhadi, K. Sedighi, Experimental heat transfer and pressure drop study on typical, perforated, V-cut and U-cut twisted tapes in a helically corrugated heat exchanger, International Communications in Heat \& Mass Transfer, 71 (2016) 126-136.

[11] Vijaypal Singh, Sunil Chamoli, Manoj Kumar, Alok Kumar, Heat transfer and fluid flow characteristics of heat exchanger tube with multiple twisted tapes and solid rings inserts, Chemical Engineering \& Processing Process Intensification, 102 (2016) 156-168.

[12] Hamed Safikhani, Farzad Abbasi, Numerical study of nanofluid flow in flat tubes fitted with multiple twisted tapes, Advanced Powder Technology, 26.6 (2015) 1609-1617.

[13] Kumar S, Dinesha P, Narayanan A, et al. Numerical investigation on the heat transfer characteristics in a circular pipe using multiple twisted tapes in laminar flow conditions [J]. Heat Transfer-Asian Research, 2019, 48 (7).

[14] Chaurasia S R, Sarviya R M. Experimental and Numerical Thermal Performance Evaluation on Helical Screw Insert in Tube with Double Strips at Laminar Flow [J]. Computational Thermal Sciences, 2020, 13 (1).

[15] S. R. Shabanian, M. Rahimi, M. Shahhosseini, A. A. Alsairafi, CFD and experimental studies on heat transfer enhancement in an air cooler equipped with different tube inserts, International Communications in Heat \& Mass Transfer, 38.3 (2011) 383-390.

[16] Erika Y. Rios-Iribe, et al, Heat transfer analysis of a non-Newtonian fluid flowing through a circular tube with twisted tape inserts, Applied Thermal Engineering, 84 (2015) 225-236.

[17] Taiwo O. Oni, Manosh C. Paul, Numerical investigation of heat transfer and fluid flow of water through a circular tube induced with divers tape inserts, Applied Thermal Engineering, 98 (2015) 157-168.
[18] Sami D. Salman, Abdul Amir H. Kadhum, Mohd S. Takriff, Abu BakarMohamad, Heat transfer enhancement of laminar nanofluids flow in a circular tube fitted with parabolic-cut twisted tape inserts, Scientific World Journal 2014. 1 (2014) 543231 .

[19] Liu P, Zheng N, Shan F, et al. Heat transfer enhancement for laminar flow in a tube using bidirectional conical strip inserts [J]. International Journal of Heat and Mass Transfer, 2018, 127 (PT.B): 1064-1076.

[20] Singh S, Pandey L, Kharkwal H, et al. Augmentation of thermal performance of heat exchanger using elliptical and circular insert with vertical twisted tape $[\mathrm{J}]$. Experimental Heat Transfer, 2019: 1-16.

[21] Mahdi Pourramezan, Hossein Ajam, Modeling for Thermal Augmentation of Turbulent Flow in a Circular Tube Fitted with Twisted Conical Strip Inserts, Applied Thermal Engineering, 105 (2016) 509-518.

[22] S. Eiamsa-Ard, K. Wongcharee, S. Sripattanapipat, 3-D Numerical simulation of swirling flow and convective heat transfer in a circular tube induced by means of loose-fit twisted tapes, International Communications in Heat \& Mass Transfer, 36.9 (2009) 947-955.

[23] Jian Guo, Aiwu Fan, Xiaoyu Zhang, Wei Liu, A numerical study on heat transfer and friction factor characteristics of laminar flow in a circular tube fitted with center-cleared twisted tape, International Journal of Thermal Sciences, 50.7 (2011) 1263-1270.

[24] V. Gnielinski, New equations for heat and mass transfer in the turbulent flow in pipes and channels, Nasa Sti/recon Technical Report A, 75.2 (1976) 8-16.

[25] Murugesan P. Turbulent Heat Transfer and Pressure Drop in Tube Fitted with Square-cut Twisted Tape [J]. Chinese Journal of Chemical Engineering, 2010.

[26] Murugesan P, Mayilsamy K, Suresh S, et al. Heat transfer and pressure drop characteristics in a circular tube fitted with and without V-cut twisted tape insert [J]. International Communications in Heat \& Mass Transfer, 2010, 38 (3): 329-334.

[27] Murugesan P, Mayilsamy K, Suresh S. Heat transfer in tubes fitted with trapezoidal-cut and plain twisted tape inserts [J]. Chemical Engineering Communications, 2011, 198 (7): 886-904. 